\title{
A physical activity program versus usual care in the management of quality of life for pre-frail older adults with chronic pain: randomized controlled trial
}

\author{
Pedro Otones ${ }^{1 *}$ D, Eva García ${ }^{2}$, Teresa Sanz ${ }^{3,4}$ and Azucena Pedraz ${ }^{2}$
}

\begin{abstract}
Background: Exercise has shown being effective for managing chronic pain and preventing frailty status in older adults but the effect of an exercise program in the quality of life of pre-frail older adults with chronic pain remains unclear. Our objective was to evaluate the effectiveness of multicomponent structured physical exercise program for pre-frail adults aged 65 years or more with chronic pain to improve their perceived health related quality of life, compared with usual care.
\end{abstract}

Methods: Open label randomized controlled trial. Participants were community-dwelling pre-frail older adults aged 65 years or older with chronic pain and non-dependent for basic activities of daily living attending a Primary Healthcare Centre. Forty-four participants were randomly allocated to a control group $(n=20)$ that received usual care or an intervention group $(n=24)$ that received an 8-week physical activity and education program. Frailty status (SHARE Frailty Index), quality of life (EuroQol-5D-5L), pain intensity (Visual Analogue Scale), physical performance (Short Physical Performance Battery) and depression (Yessavage) were assessed at baseline, after the intervention and after 3 months follow-up. The effect of the intervention was analysed by mean differences between the intervention and control groups.

Results: The follow-up period (3 months) was completed by 32 patients (73\%), 17 in the control group and 15 in the intervention group. Most participants were women (78.1\%) with a mean age (standard deviation) of 77.2 (5.9) years and a mean pain intensity of 48.1 (24.4) $\mathrm{mm}$. No relevant differences were found between groups at baseline. After the intervention, mean differences in the EuroQol Index Value between control and intervention groups were significant (- $0.1995 \% \mathrm{Cl}(-0.33-0.04))$ and remained after 3 months follow-up (- 0.21 95\% Cl(-0.37- -0.05$)$ ). Participants in the exercise group showed better results in pain intensity and frailty after the intervention, and an improvement in physical performance after the intervention and after 3 months.

Conclusions: An eight-week physical activity and education program for pre-frail older adults with chronic pain, compared with usual care, could be effective to improve quality of life after the intervention and after threemonths follow-up.

(Continued on next page)

\footnotetext{
* Correspondence: pedro.otones@salud.madrid.org

${ }^{1}$ San Andrés Primary Care Center, Gerencia Asistencial de Atención Primaria, Alberto Palacios, 22, 28021 Madrid, Spain

Full list of author information is available at the end of the article
}

C The Author(s). 2020 Open Access This article is licensed under a Creative Commons Attribution 4.0 International License, which permits use, sharing, adaptation, distribution and reproduction in any medium or format, as long as you give appropriate credit to the original author(s) and the source, provide a link to the Creative Commons licence, and indicate if changes were made. The images or other third party material in this article are included in the article's Creative Commons licence, unless indicated otherwise in a credit line to the material. If material is not included in the article's Creative Commons licence and your intended use is not permitted by statutory regulation or exceeds the permitted use, you will need to obtain permission directly from the copyright holder. To view a copy of this licence, visit http://creativecommons.org/licenses/by/4.0/. The Creative Commons Public Domain Dedication waiver (http://creativecommons.org/publicdomain/zero/1.0/) applies to the data made available in this article, unless otherwise stated in a credit line to the data. 
(Continued from previous page)

Study registration details: This study was retrospectively registered in ClinicalTrials.gov with the identifier NCT04045535.

Keywords: Frailty, Chronic pain, Exercise, Quality of life, Aged, Nursing education

\section{Background}

Chronic pain $(\mathrm{CP})$ is one of the most frequent, costly and incapacitating conditions in older adults [1]. It is usually accompanied in older adults with atypical symptoms, comorbidities, polypharmacy and increased risk of interactions and secondary effects, which makes its management complex [2]. Important age modifications in pain perception has been described with a reduction in the descending inhibitory capacity and an increase in pain alert thresholds due to an impairment of $A \delta$ fibres and a decline in concentration of catecholamines, GABA and opioid receptors $[2,3]$. Those differences make pain assessment and treatment complex. The failure to effectively identify and manage pain could result in a reduced quality of life and could impact negatively on the relationship between the older person and the caregiver [4].

Chronic Pain is a highly prevalent condition. The last Global Burden of Disease identified among the commonest chronic conditions (over 1\% of global prevalence) several primary pain conditions: migraines, low back pain, neck pain, musculoskeletal conditions or osteoarthritis [5]. The prevalence of CP in Europe among older adults according to The Survey of Health, Ageing and Retirement in Europe (SHARE) was 35.7\% (95\% CI 34.9-36.5) and this prevalence was higher in women $(41.3 \%$; $95 \%$ CI 40.2-42.4) [6]. Chronic Pain conditions were associated with frailty, poor mobility, depression, cognitive impairment, falls, and low physical activity (PA) levels [7].

The World Health Organization (WHO) recommends that all people aged 65 years or above should do $150 \mathrm{~min}$ or more of moderate-intensity physical activity per week or 75 min of higher intensity PA [8]. Nevertheless, exercise participation declines progressively through adult life [9]. Physical inactivity is after high blood pressure, tobacco consumption and high blood glucose concentrations, the fourth most important risk of mortality worldwide [10]. It has been shown that regular PA participation reduces the risk of coronary heart disease, diabetes, hypertension, stroke, some types of cancer and depression [8]. It can also increase years living independently, reduce disability, improve quality of life and reduce mortality for all causes [11]. People who participate in physical exercise programs are less frequently classified as frail [12].

Frailty is a common and potentially incapacitating condition in older adults. It is defined as a clinical state in which an individual's vulnerability for developing dependency and/or mortality when exposed to a stressor increases [13]. It is associated with older age, female sex, lower incomes or polypharmacy [14]. Frailty should be assessed by validated tools, that usually characterize patients in three types, according to their functional status: frail, pre-frail or robust [13]. A strong association between a frail or pre-frail status and lower quality of life has been reported by several investigations [15]. The prevalence of diabetes, heart disease, osteoporosis, lung disease and stroke is twice that in robust, and the prevalence of having suffered falls in the previous year is three to four times higher [16]. Falls are one of the major consequences of frailty. They are the second leading cause of accidental deaths worldwide [17] and more than 70\% of falls have clinic consequences like fractures or injuries [18]. Older women with lower levels of physical activity report higher risk of falls than women that usually participate in physical activities [19].

An association between suffering from $\mathrm{CP}$ and being classified as frail or pre-frail has been reported in several investigations $[20,21]$. It has also been reported that adults with CP participate in less PA than individuals with no pain [22]. Nevertheless, it has been reported that physical activity performance may change pain modulation in older adults [23]. Due to the impact in quality of life of frailty, CP and lower PA and the potential benefits of PA programs for frailty prevention and $\mathrm{CP}$ management our aim is to evaluate the effectiveness of a multicomponent structured physical exercise program for adults aged 65 years or more, classified as pre-frail and with chronic pain to improve their perceived health related quality of life, compared with usual care in primary health care.

\section{Methods \\ Design}

This study was designed as a parallel group open label randomized controlled trial with repeated measures and 3 months follow-up to determine the effect of an eightweek physical activity program for pre-frail older adults with chronic pain. This study adheres to the CONSORT Statement for Non-pharmacologic Treatment Interventions [24].

\section{Participants and setting}

Data were collected between May 2018 and June 2019 in a Primary Health Care Centre in Madrid, Spain. All participants classified as pre-frail $(n=59 ; 47$ women and 12 men) in a previous cross-sectional investigation about frailty status in older adults with chronic pain were 
invited to participate in this randomized controlled trial. They were included if they accepted to participate and met the inclusion criteria. Participants were included if they were older adults aged 65 years or older with chronic pain for more than 3 months and classified as pre-frail by the SHARE Frailty Index [25]. Participants were excluded if they were dependent for activities of daily living (ADL). Dependence for ADL has been measured with the Barthel ADL index [26, 27]; participants with index result under 90 were excluded. They were also excluded if they were classified as a homebound person. It is defined as persons who never or rarely left the home in the past month [28]. Participants unable to answer questionnaires independently, due to mental illness, dementia or language barriers were also excluded. Participants were excluded if they were institutionalized, if they lived out of the area of the investigation for more than 6 months per year or if they were participating in other clinical trials. Simple randomization was developed using the program Epidat 4.2 to randomly assign participants after signing the written consent to an intervention group or control group. Nor participants or researchers knew the allocation group when they were invited to participate and signed the written consent.

\section{Control group}

Participants in the control group received usual practice in Primary Care, which included an assessment of dependence with Barthel Index, frailty assessment with Short Physical Performance Battery and structured education about nutrition, physical exercise, moderate sun exposure, falls prevention and medication use. They were invited to participate in the physical activity program after the trial was finished if results were positive and they accepted.

\section{Intervention group}

Participants in the intervention group received an eightweek physical activity and education program in addition to usual practice in Primary Care. The physical activity and education program was adapted from a similar program developed by Tse et al. (2014) for older persons living in nursing homes that reduced pain intensity and improved emotional wellness of the participants reporting better results in happiness, loneliness, life satisfaction and depression [29].

The physical activity and education program was developed once a week for 8 weeks in a conference and multi-function room in the Primary Care Centre. Each session lasted for $60 \mathrm{~min}, 15 \mathrm{~min}$ for warming-up and 45 min for exercises that changed in each session: shoulder and neck exercises; back exercises; knee and ankle exercises; hip exercises; balance exercises; falls prevention education; questions, answers and reflections; revision, reflections, evaluation and goodbye. Participants made suggested exercises accompanied by the instructor. After each session, they received a document with pictures that described the exercises of the day.

\section{Measures}

The main outcome variable in this study was perceived health-related quality of life. Data on pain intensity, frailty status, physical performance, depression, basic activities of daily living and satisfaction with the intervention were also recorded.

\section{Quality of life}

Participants' perceived health related quality of life was assessed with the EuroQol 5D-5L (EQ-5D-5L) [30]. This questionnaire consists of five dimensions of health (mobility, self-care, usual activities, pain/discomfort and anxiety/depression) with five levels of problems. It also includes a Visual Analogue Scale with a range 0-100 in which higher scores indicates better quality of life. The results of the five dimensions are transformed in an index value by a calculator with different value sets depending on the setting country which has been validated in our context [31].

\section{Pain intensity}

It was assessed with the Visual Analogue Scale of the Short Form of McGill Pain Questionnaire [32] ranging from "no pain $=0 \mathrm{~mm}$ " to "unwilling pain $=100 \mathrm{~mm}$ ". Scores were calculated to the nearest millimetre with a ruler. Minimally clinically important difference for VAS is $23 \mathrm{~mm}$ [33].

\section{Frailty}

Subjects were classified as frail, pre-frail or robust according to the five criteria of the Survey of Health, Ageing and Retirement in Europe Frailty Index (SHARE-FI) [25]:

Exhaustion: by the positive response to the question: 'In the last month, have you had too little energy to do the things you wanted to do?

Weight loss: by reporting a diminution in desire for food in response to the question: 'What has your appetite been like?'

Weakness: assessed by handgrip strength using a dynamometer twice in each hand. The highest measurement is selected.

Slowness: by positive answer to one of the following questions: 'Because of a health problem, do you have difficulty walking 100 meters or climbing one flight of stairs without resting?'

Low activity: assessed by the question: 'How often do you engage in activities that require a low or moderate level of energy such as gardening, cleaning the car or doing a walk?' 
The aim of the SHARE-FI is to summarize those variables in a single discreet factor (DFactor) with three classes: non-frail, pre-frail and frail. Changes in 0.5 DFactor score (DFS) were described as an improvement in frailty status [34]. The formula for the DFS is different in men and women:

Women: If predicted DFS $<0.31$, NON-FRAIL; if predicted DFS $<2.13$, PRE-FRAIL; if predicted DFS $<6$, FRAIL.

Men: If predicted DFS $<1.21$, NON-FRAIL; if predicted DFS $<3.00$, PRE-FRAIL; if predicted DFS $<7$, FRAIL.

\section{Physical performance}

The Short Physical Performance Battery (SPPB) was used [35]. It consists of three tests: balance skills, gait speed and chair stands. Balance is assessed using foots side-by-side, semi-tandem and tandem stands. Gait speed was tested with two four meters walk with or without mobility devices. The ability to stand from a chair and return to seated position five times with arms crossed was also tested. A final score was calculated ranging from zero (worst performance) to twelve (best performance).

\section{Basic activities of daily living}

Basic Activities of Daily Living (bADL) dependence was assessed by Barthel ADL index [26, 27]. It assesses the help needed with ten variables: feeding, bathing, grooming, dressing, urinary incontinence, faecal incontinence, toilet use, transfers bed to chair, mobility and climbing stairs.

\section{Depression}

Depression was assessed using the 5-items Geriatric Depression Scale [36]. It comprises five questions with yes or no answers. It is a commonly used tool in Primary Care and it has been validated in our context [37].

\section{Further measurements}

Satisfaction with the program was assessed using the 8items Clients Satisfaction Questionnaire (CSQ-8) [38]. It is a generic questionnaire with 8 questions ( 4 of them with reverse score) about participants' satisfaction with the intervention received, if they feel that the intervention was useful and if they would recommend it to their counterparts.

Sociodemographic characteristics like age, sex or if participants live alone or in family were also recorded.

\section{Statistical analysis}

Data were recorded in an electronic database for analysis. Qualitative and categorical variables were described using numbers of participants $(\mathrm{N})$ and percentages, and continuous variables were described using means and standard deviations (SDs). Chi-square test was used to analyse the differences in the qualitative data between the intervention and control group. T-test analyses were used to compare the differences of the quantitative outcomes' variables. We calculated the difference between the means in each group, post-intervention time and at 3-month follow-up with their 95\% CI. All differences were assessed for their clinical significance as shown in previous studies. All analyses were performed using IBM SPSS Statistics v.23.

\section{Ethics}

All participants agreed to participate in the study by signing a written informed consent. The protocol of the investigation was registered in the database of clinical studies ClinicalTrials.gov (ClinicalTrials.gov Identifier: NCT04045535) and it was approved by two independent ethical research committees from a hospital (Hospital 12 de Octubre, code: 18/170) and a university (Universidad Autónoma de Madrid, code: CEI-88-1659).

\section{Results}

Participants' demographic and clinical characteristics Fifty-nine pre-frail older adults with chronic pain were invited to participate in the study. Fifteen patients refused to participate and 44 were randomly assigned to the control or intervention group. Finally, 32 participants finished the randomized controlled trial and were analysed, this was the result of a loss of participants in both groups during the 3 months follow-up due to not being able to come to the intervention (intervention group, $n=5$ ), not coming to follow-up (control group, $n=5$ ), hospitalisation (intervention group, $n=1$ ) and illness of a relative (intervention group, $n=1$ ) (Fig. 1).

Participants had a mean (Standard Deviation, SD) age of 77.2 (5.9) years and a mean (SD) pain intensity of 48.1 (24.4) $\mathrm{mm}$. There were a majority of women, 78.1 and $21.9 \%$ were men. No statistically significant differences were found between control group and intervention group excluding mean age of intervention group participants, which were 4.9 years older than control group participants (Table 1).

\section{Primary outcomes}

As shown in Table 1, no baseline (T0) clinical differences were found between intervention and control groups in quality of life index value, VAS, or percentage of moderately, severely, or extremely affected EQ-5D-5L dimensions. At $\mathrm{T} 1$ both groups improved their results in the EQ-5D-5L index value. The mean score (SD) of the intervention group $(0.78(0.12))$ was significantly higher than the score of the control group $(0.59(0.25))$. After the 3 months follow-up (T2), differences between results of the intervention group $(0.77(0.13))$ and the control group $(0.56(0.28))$ remained being statistically significant (Table 2). 


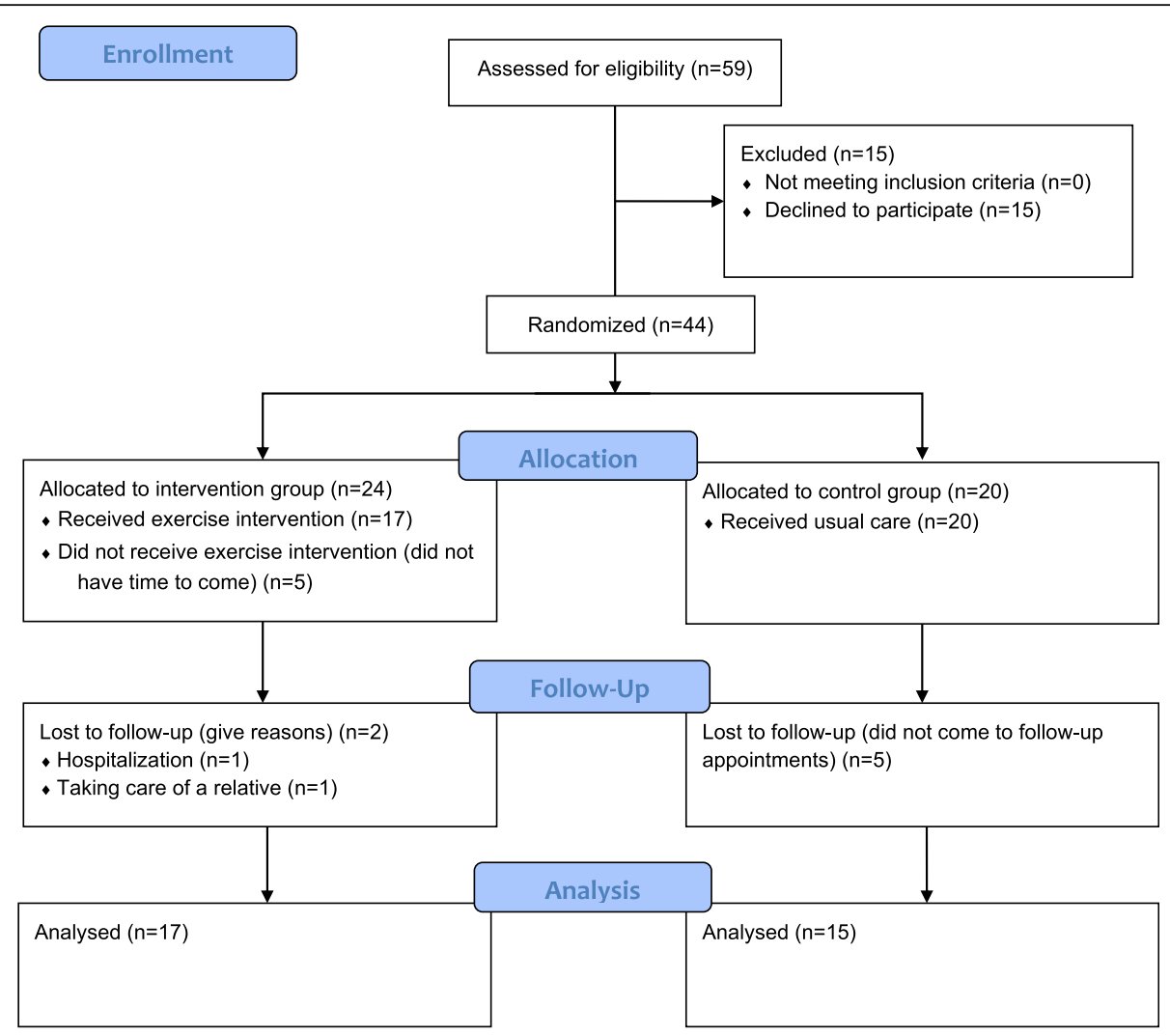

Fig. 1 CONSORT flow diagram

Pain intensity measures for the intervention and control groups

After finishing the physical activity program (T1), differences in mean (SD) pain intensity were found between the intervention group $(29.88(14.94))$ and the control group (52.00 (30.19)), as shown in Table 2. At T2, differences did not remain being statistically significant, mean (SD) pain intensity for the intervention group (38.18 (20.65)) and for the control group (51.67 (27.90)) was comparable to baseline measures.

\section{Physical performance measures for the intervention and control groups}

After the completion of the physical activity program (T1), compared to baseline, the mean (SD) result of the SPPB was significantly higher for the intervention group (8.18 (1.78), $p=.01)$. These results remained after 3 months follow-up (8.41 (1.77), $p<.01)$. Control group also improved the results of the SPPB at T1 (8.47 (2.26), $p=.06)$ and T2 (8.8 (2.54), $p=.03)$ but not as significantly as the intervention group. No statistically significant differences were found between groups (Table 2).

Frailty status for the intervention and control groups At T0, all participants were classified as pre-frail. After the intervention (T1), $58.8 \%$ of the participants in the intervention group were classified as non-frail and $41.2 \%$ as pre-frail. In the control group $80 \%$ of participants remained as pre-frail at $\mathrm{T} 1,13.3 \%$ were classified as frail and $6.7 \%$ as non-frail. At T2, most participants of both groups $(70.6 \%$ intervention group and $73.3 \%$ in control group) were classified as pre-frail but there were more participants classified as non-frail in the intervention group than in the control group (23.5\% vs $13.3 \%)$.

\section{Further measures}

No differences were found between the intervention and control groups in depression or bADL, as shown in Table 2.

Participants reported a high satisfaction with the intervention with a mean satisfaction of $30.69 / 32$ points. No side effects were reported by the participants during the physical activity education program or during the threemonths follow-up.

\section{Discussion}

In this randomized controlled trial, we found that compared to the control group, participants who received a physical activity intervention reported better quality of life, better frailty status and lower pain intensity. Furthermore, participants in the intervention group reported better physical performance after the intervention and after 
Table 1 Baseline demographic and clinical characteristics by group

\begin{tabular}{|c|c|c|c|c|c|}
\hline & & $\begin{array}{l}\text { Total } \\
(n=32)\end{array}$ & $\begin{array}{l}\text { Intervention } \\
(n=17)\end{array}$ & $\begin{array}{l}\text { Control } \\
(n=15)\end{array}$ & $p$ \\
\hline Sex & n (\%) & & & & \\
\hline Male & & 7 (21.9\%) & $5(29.4 \%)$ & $2(13.3 \%)$ & .27 \\
\hline Female & & $25(78.1 \%)$ & $12(70.6 \%)$ & 13 (86.7\%) & \\
\hline Age & Mean (SD) & $77.2(5.9)$ & $79.5(4.2)$ & $74.6(6.5)$ & .02 \\
\hline \multirow[t]{2}{*}{ Pain VAS } & Mean (SD) & $48.1(24.4)$ & 41.9 (18.3) & $55.2(28.9)$ & .13 \\
\hline & Median (IQR) & $50.5(35-69.75)$ & $40(29.5-57.5)$ & 68 (39-73) & \\
\hline SPPB & Mean (SD) & $7.1(1.9)$ & $6.6(1.7)$ & $7.7(1.9)$ & .11 \\
\hline \multicolumn{6}{|l|}{ Quality of life } \\
\hline \multirow[t]{2}{*}{ EQ-5D VAS } & Mean (SD) & $60.9(18.7)$ & $60.5(17.7)$ & $61.3(20.4)$ & .91 \\
\hline & Median (IQR) & $60(50-73.5)$ & $60(50-65)$ & $60(50-80)$ & \\
\hline \multirow[t]{2}{*}{ Index value } & Mean (SD) & $.61(.22)$ & $.67(.13)$ & $.55(.28)$ & .12 \\
\hline & Median (IQR) & $0.69(0.51-0.75)$ & $0.7(0.56-0.76)$ & $0.69(0.46-0.74)$ & \\
\hline Mobility & n (\%) & $11(34.4 \%)$ & $4(23.5 \%)$ & 7 (46.7\%) & .11 \\
\hline Self-care & n (\%) & $4(12.5 \%)$ & 1 (5.9\%) & $3(20 \%)$ & .86 \\
\hline Usual activ. & n (\%) & $12(37.5 \%)$ & $6(35.3 \%)$ & $6(40 \%)$ & .45 \\
\hline Pain & n (\%) & $22(68.8 \%)$ & $12(70.6 \%)$ & $10(66.7 \%)$ & .88 \\
\hline Anxiety & n (\%) & $12(37.5 \%)$ & $6(35.3 \%)$ & $6(40 \%)$ & .31 \\
\hline Yesavage & Mean (SD) & $1.5(1.2)$ & $1.4(1.2)$ & $1.8(1.2)$ & .39 \\
\hline Barthel & Mean (SD) & $97.6(3.1)$ & $97.6(3.1)$ & $97.6(3.2)$ & .99 \\
\hline Number of medications & Mean (SD) & $9.2(3.8)$ & $9.3(4.4)$ & $9.2(3.1)$ & .92 \\
\hline Live with & n (\%) & & & & \\
\hline Family & & $4(12.5 \%)$ & $3(17.6 \%)$ & $1(6.7 \%)$ & \\
\hline Partner & & $17(53.1 \%)$ & $8(47.1 \%)$ & $9(60.0 \%)$ & .60 \\
\hline Alone & & $11(34.4 \%)$ & $6(35.3 \%)$ & $5(33.3 \%)$ & \\
\hline
\end{tabular}

VAS Visual Analogue Scale, SD Standard Deviation, IQR Inter-quartile range, SPPB Short Physical performance battery

Table 2 Mean differences between intervention and control groups

\begin{tabular}{|c|c|c|c|c|c|c|}
\hline & \multicolumn{3}{|c|}{ Post-intervention (T1) } & \multicolumn{3}{|c|}{3 months follow-up (T2) } \\
\hline & $\begin{array}{l}\text { Mean } \\
\text { differences }\end{array}$ & $95 \% \mathrm{Cl}$ & $p$ & Mean differences & $95 \% \mathrm{Cl}$ & $p$ \\
\hline \multicolumn{7}{|l|}{ Quality of life } \\
\hline Index value & -0.19 & $(-0.33--0.04)$ & .02 & -0.21 & $(-0.37--0.05)$ & .01 \\
\hline EQ-5D VAS & -9.1 & $(-23.58-5.39)$ & .21 & -4.3 & $(-15.22-6.63)$ & .43 \\
\hline \multicolumn{7}{|l|}{ Frailty } \\
\hline DFS Men & -1.19 & $(-3.46-1.09)$ & .24 & 0.1 & $(-2.16-2.36)$ & .91 \\
\hline DFS Women & -1.22 & $(-1.96--0.48)$ & .00 & -0.82 & $(-1.54--0.10)$ & .03 \\
\hline VAS pain & 22.12 & $(4.18-40.06)$ & .02 & 13.49 & $(-4.09-31.07)$ & .13 \\
\hline SPPB & 0.29 & $(-1.17-1.15)$ & .69 & 0.39 & $(-1.23-2.00)$ & .62 \\
\hline Yesavage & -0.12 & $(-1.18-0.93)$ & .82 & -0.28 & $(-1.13-0.58)$ & .51 \\
\hline Barthel & -0.27 & $(-2.55-2.00)$ & .81 & -1.65 & $(-5.06-1.76)$ & .33 \\
\hline
\end{tabular}


3 months follow-up than at baseline. These results are consistent with those of other studies on older adults. The effect of physical activities in reversing frailty status, reducing the fear of falls or improving mobility have been reported by previous systematic reviews [39]. Exercise and nutrition interventions showed being more effective to reverse frailty status in community-dwelling frail women than only nutritional interventions [40].

Our trial found an improvement in quality of life assessed with EQ-5D-5L in the intervention group of 0.10 points at $\mathrm{T} 1$ and 0.09 points at $\mathrm{T} 2$ from baseline. Previous investigations found that a change of 0.03 points was related to a change on the global perceived effect of a treatment in patients with chronic low-back pain [41] and that minimal clinically important difference (MCID) for improvement was 0.07 points in patients with osteoarthritis [42]. Previous studies showed an association between quality of life and physical performance, patients with lower scores in the SPPB also reported worse results in the EQ-5D-5L index value [43]. Reporting increased pain sites or pain severity was also associated with poorer SPPB results [44]. Our research found an improvement in the physical performance assessed with the SPPB in the group that received the exercise intervention. The improvement was higher than these identified as substantial changes in previous investigations [45].

Although no differences in depression assessed with the 5-Item Geriatric Depression Scale were found, we found statistically significant differences between control and intervention group in the anxiety/depression dimension of EQ-5D-5L. These results are consistent with those of the investigation of Tse et al. (2014) [29]. They found significant changes in happiness, loneliness, life satisfaction and depression in the exercise group. A recent qualitative research revealed that older adults participating in a community-based program of socialization, health education exercise and walking reduced their feelings of loneliness and social isolation [46].

A recent overview of 21 Cochrane Reviews with 381 included studies found that, although further research is required, exercise interventions produce small-to-moderate positive effect in pain severity and physical function and consequently quality of life, with few adverse events and some effects in psychological function [47]. In our research, participants in the intervention group showed a reduction of 12.06 $\mathrm{mm}$ of the VAS at T1, but that reduction in pain intensity was not maintained after the three-months follow-up. Although there were differences in pain intensity in the intervention group between T0 and $\mathrm{T} 1$ and those differences were statistically significant, the small effect of the intervention in pain intensity made that clinical relevance could be questionable.
Despite the positive effects of the physical activity program, this study has several limitations. First, the number of participants is limited, which makes it difficult to generalize the results of the intervention. They were recruited from a previous observational investigation about prevalence of frailty in patients with chronic pain and it could not include all pre-frail older adults with chronic pain of the study area. Moreover, there is no description of painkillers use and the location, cause, and period of chronic pain. Second, the investigation was developed just in one Primary Health Care Center, which could affect the external validity of the results. Third, due to the characteristics of the intervention, it was impossible to blind participants or researchers. When participants were proposed to participate in the investigation nor them or the researcher knew the group they were going to be assigned to.

Future research could be necessary to solve the limitations that were found in this trial, with a larger number of participants, differentiating period, grade, and area of chronic pain, and including not only pre-frail participants but also frail and robust ones. A multicenter research could include participants with different socioeconomic characteristics and living in urban or rural areas which could be interesting to evaluate how physical activity affects older adults with chronic pain in different environments.

\section{Conclusion}

An eight-week physical activity and education program for pre-frail older adults with chronic pain, compared with usual care, could be effective to improve quality of life after the intervention and after three-months followup. Participants who received the physical activity and education program also showed better physical performance and reported high satisfaction with the intervention.

\section{Abbreviations \\ ADL: Activities of daily living; bADL: Basic Activities of Daily Living; Cl: Confidence Interval; CONSORT: Consolidated Standards of Reporting Trials; CP: Chronic Pain; CSQ-8: Client Satisfaction Questionnaire 8 Items; DFS: Discreet factor Score; EQ-5D-5L: EuroQol 5 dimensions and 5 levels.; GABA: Gamma-Aminobutyric acid.; IQR: Inter-quartile range.; MCID: Minimal clinically important difference.; PA: Physical Activity.; SD: Standard Deviation; SHARE: Survey of Health, Ageing and Retirement in Europe; SHARE-FI: Survey of Health, Ageing and Retirement in Europe Frailty Index; SPPB: Short Physical Performance Battery; SPSS: Statistical Package for Social Sciences; VAS: Visual Analogue Scale; WHO: World Health Organization}

\section{Acknowledgements}

Not applicable.

\section{Authors' contributions}

PO was the leader of the analysis, writing and revising the manuscript. AP and EG participated in the design of the study and its coordination. TS participated in the analysis of the data. All authors revised the manuscript, read, and approved the final version.

\section{Funding}

This work did not receive any public or private funding. 


\section{Availability of data and materials}

The datasets generated and analyzed during the current study are not publicly available due to not having consent from the patients to disclose raw data.

\section{Ethics approval and consent to participate}

All participants agreed to participate in the study by signing a written informed consent. The protocol of the investigation was approved by two independent ethical research committees from a hospital (Hospital 12 de Octubre, code: 18/170) and a university (Universidad Autónoma de Madrid, code: CEl-88-1659).

\section{Consent for publication}

Not applicable.

\section{Competing interests}

The authors declare that they have no competing interests.

\section{Author details}

${ }^{1}$ San Andrés Primary Care Center, Gerencia Asistencial de Atención Primaria, Alberto Palacios, 22, 28021 Madrid, Spain. ${ }^{2}$ Nursing Department, Universidad Autónoma de Madrid, Madrid, Spain. ${ }^{3}$ Research Unit, Gerencia Asistencial de Atención Primaria, Madrid, Spain. ${ }^{4}$ Health Services Research on Chronic Patients Network (REDISSEC), Instituto Salud Carlos III, Madrid, Spain.

\section{Received: 7 June 2020 Accepted: 30 September 2020}

Published online: 08 October 2020

\section{References}

1. Bicket MC, Mao J. Chronic pain in older adults. Anesthesiol Clin. 2015;33: 577-90. https://doi.org/10.1016/j.anclin.2015.05.011.

2. Paladini A, Fusco M, Coaccioli S, Skaper SD, Varrassi G. Chronic pain in the elderly: the case for new therapeutic strategies. Pain Physician. 2015;18: E863-76 http://www.ncbi.nlm.nih.gov/pubmed/26431140. Accessed 25 May 2019.

3. Gibson SJ, Farrell M. A review of age differences in the neurophysiology of nociception and the perceptual experience of pain. Clin J Pain. 2004;20:22739. https://doi.org/10.1097/00002508-200407000-00004.

4. Schofield P. The Assessment of Pain in Older People: UK National Guidelines. Age Ageing. 2018;47(suppl_1):i1-22. https://doi.org/10.1093/ ageing/afx192.

5. Rice ASC, Smith BH, Blyth FM. Pain and the global burden of disease. Pain. 2016;157:791-6. https://doi.org/10.1097/j.pain.0000000000000454.

6. Cimas M, Ayala A, Sanz B, Agulló-Tomás MS, Escobar A, Forjaz MJ. Chronic musculoskeletal pain in European older adults: Cross-national and gender differences. Eur J Pain (United Kingdom). 2018;22:333-45. https://doi.org/10. 1002/ejp.1123.

7. Blyth FM, Noguchi N. Chronic musculoskeletal pain and its impact on older people. Best Pract Res Clin Rheumatol. 2017;31(2):160-8. https://doi.org/10. 1016/j.berh.2017.10.004.

8. World Health Organization. Global recommendations on physical activity for health: World Health Organization; 2010. https://www.who.int/ dietphysicalactivity/factsheet_recommendations/en/. Accessed 26 Aug 2019.

9. McPhee JS, French DP, Jackson D, Nazroo J, Pendleton N, Degens H. Physical activity in older age: perspectives for healthy ageing and frailty. Biogerontology. 2016;17:567-80. https://doi.org/10.1007/s10522-016-9641-0.

10. World Health Organization. Global health risks: mortality and burden of disease attributable to selected major risks. World Health Organization. 2009. https://apps.who.int/iris/handle/10665/44203. Accessed 13 Mar 2020.

11. Sun F, Norman IJ, While AE. Physical activity in older people: a systematic review. BMC Public Health. 2013;13:449. https://doi.org/10.1186/1471-245813-449.

12. Yamada M, Arai H, Sonoda T, Aoyama T. Community-based exercise program is cost-effective by preventing care and disability in Japanese frail older adults. J Am Med Dir Assoc. 2012;13:507-11. https://doi.org/10.1016/J. JAMDA.2012.04.001.

13. Morley JE, Vellas B, van Kan GA, Anker SD, Bauer JM, Bernabei R, et al. Frailty consensus: a call to action. J Am Med Dir Assoc. 2013;14:392-7. https://doi. org/10.1016/j.jamda.2013.03.022.
14. Coelho T, Paúl C, Gobbens RJJ, Fernandes L. Determinants of frailty: The added value of assessing medication. Front Aging Neurosci. 2015;7(APR):56. https://doi.org/10.3389/fnagi.2015.00056.

15. Kojima G, lliffe S, Jivraj S, Walters K. Association between frailty and quality of life among community-dwelling older people: a systematic review and meta-analysis. J Epidemiol Community Health. 2016;70:716-21.

16. Bandeen-Roche K, Seplaki CL, Huang J, Buta B, Kalyani RR, Varadhan R, et al. Frailty in older adults: a nationally representative profile in the United States. J Gerontol Ser A Biol Sci Med Sci. 2015;70:1427-34. https:/doi.org/10.1093/gerona/glv133.

17. WHO. Falls. 2018. https://www.who.int/news-room/fact-sheets/detail/falls. Accessed 12 Mar 2020

18. Ministerio de Sanidad Igualdad y Servicios sociales. Documento de consenso sobre prevención de fragilidad y caídas en la persona mayor: Estrategia de Promoción de la Salud y Prevención en el SNS. Informes estudios e investigación. 2013:1-85 http://www.msssi.gob.es/profesionales/ saludPublica/prevPromocion/Estrategia/docs/FragilidadyCaidas_ personamayor.pdf. Accessed 29 Mar 2019

19. Buchner DM, Rillamas-Sun E, Di C, LaMonte MJ, Marshall SW, Hunt J, et al. Accelerometer-measured moderate to vigorous physical activity and incidence rates of falls in older women. J Am Geriatr Soc. 2017;65:2480-7. https://doi.org/10.1111/jgs.14960.

20. Saraiva MD, Suzuki GS, Lin SM, de Andrade DC, Jacob-Filho W, Suemoto CK. Persistent pain is a risk factor for frailty: a systematic review and metaanalysis from prospective longitudinal studies. Age Ageing. 2018;47:785-93. https://doi.org/10.1093/ageing/afy104.

21. Otones Reyes P, García Perea E, Pedraz MA. Chronic pain and frailty in community-dwelling older adults: a systematic review. Pain Manag Nurs. 2019;20:309-15. https://doi.org/10.1016/j.pmn.2019.01.003.

22. Dansie EJ, Turk DC, Martin KR, Van Domelen DR, Patel KV. Association of chronic widespread pain with objectively measured physical activity in adults: findings from the national health and nutrition examination survey. J Pain. 2014;15:507-15. https://doi.org/10.1016/j.jpain.2014.01.489.

23. Naugle KM, OhIman T, Naugle KE, Riley ZA, Keith NCR. Physical activity behavior predicts endogenous pain modulation in older adults. Pain. 2017; 158:383-90. https://doi.org/10.1097/j.pain.0000000000000769.

24. Boutron I, Altman DG, Moher D, Schulz KF, Ravaud P. CONSORT NPT Group. CONSORT Statement for Randomized Trials of Nonpharmacologic Treatments: A 2017 Update and a CONSORT Extension for Nonpharmacologic Trial Abstracts. Ann Intern Med. 2017;167:40-7. https:// doi.org/10.7326/M17-0046.

25. Romero-Ortuno R, Walsh CD, Lawlor BA, Kenny RA. A frailty instrument for primary care: findings from the survey of health, ageing and retirement in Europe (SHARE). BMC Geriatr. 2010;10:57. https://doi.org/ 10.1186/1471-2318-10-57.

26. Shah S, Vanclay F, Cooper B. Improving the sensitivity of the Barthel index for stroke rehabilitation. J Clin Epidemiol. 1989:42:703-9. https://doi.org/10. 1016/0895-4356(89)90065-6.

27. Barthel D, Mahoney F. Functional evaluation: the Barthel index. Md State Med J. 1965;14:56-61 Used with permission.

28. Ornstein KA, Leff B, Covinsky KE, Ritchie CS, Federman AD, Roberts L, et al. Epidemiology of the homebound population in the United States. JAMA Intern Med. 2015;175:1180-6. https://doi.org/10.1001/ jamainternmed.2015.1849.

29. Tse MMY, Tang SK, Wan VTC, Vong SKS. The effectiveness of physical exercise training in pain, mobility, and psychological well-being of older persons living in nursing homes. Pain Manag Nurs. 2014;15:778-88. https:// doi.org/10.1016/j.pmn.2013.08.003.

30. Devlin NJ, Brooks R. EQ-5D and the EuroQol group: past, present and future. Appl Health Econom Health Policy. 2017;15:127-37. https://doi.org/10.1007/ s40258-017-0310-5.

31. van Hout B, Janssen MF, Feng Y-S, Kohlmann T, Busschbach J, Golicki D, et al. Interim scoring for the EQ-5D-5L: mapping the EQ-5D-5L to EQ-5D-3L value sets. Value Health. 2012;15:708-15. https://doi.org/10.1016/j.jval.2012. 02.008 .

32. Melzack R. The short-form McGill pain questionnaire. Pain. 1987;30:191-7. https://doi.org/10.1016/0304-3959(87)91074-8.

33. Olsen MF, Bjerre E, Hansen MD, Tendal B, Hilden J, Hróbjartsson A. Minimum clinically important differences in chronic pain vary considerably by baseline pain and methodological factors: systematic review of empirical studies. J Clin Epidemiol. 2018;101:87-106.e2. https://doi.org/10.1016/j. jclinepi.2018.05.007. 
34. Luger E, Dorner TE, Haider S, Kapan A, Lackinger C, Schindler K. Effects of a Home-Based and Volunteer-Administered Physical Training, Nutritional, and Social Support Program on Malnutrition and Frailty in Older Persons: A Randomized Controlled Trial. J Am Med Dir Assoc. 2016;17:671.e9-671.e16. https://doi.org/10.1016/j.jamda.2016.04.018.

35. Guralnik JM, Simonsick EM, Ferrucci L, Glynn RJ, Berkman LF, Blazer DG, et al. A short physical performance battery assessing lower extremity function: association with self-reported disability and prediction of mortality and nursing home admission. J Gerontol. 1994;49:M85-94. https://doi.org/ 10.1093/geronj/49.2.M85.

36. Rinaldi P, Mecocci P, Benedetti C, Ercolani S, Bregnocchi M, Menculini G, et al. Validation of the five-item geriatric depression scale in elderly subjects in three different settings. J Am Geriatr Soc. 2003;51:694-8. https://doi.org/ 10.1034/j.1600-0579.2003.00216.x.

37. Ortega Orcos R, Salinero Fort MA, Kazemzadeh Khajoui A, Vidal Aparicio $S$, de Dios del Valle R. Validación de la versión española de 5 y 15 ítems de la Escala de Depresión Geriátrica en personas mayores en Atención Primaria. Rev Clínica Española. 2007;207:559-62. https://doi.org/10.1016/S00142565(07)73477-X.

38. Roberts RE, Attkisson CC. Assessing client satisfaction among hispanics. Eval Program Plann. 1983;6:401-13. https://doi.org/10.1016/0149-7189(83)90019-8.

39. de Labra C, Guimaraes-Pinheiro C, Maseda A, Lorenzo T, Millán-Calenti JC. Effects of physical exercise interventions in frail older adults: a systematic review of randomized controlled trials. BMC Geriatr. 2015;15:154. https://doi. org/10.1186/s12877-015-0155-4.

40. Kwon J, Yoshida Y, Yoshida H, Kim H, Suzuki T, Lee Y. Effects of a Combined Physical Training and Nutrition Intervention on Physical Performance and Health-Related Quality of Life in Prefrail Older Women Living in the Community: A Randomized Controlled Trial. J Am Med Dir Assoc. 2015;16: 263.e1-8. https://doi.org/10.1016/j.jamda.2014.12.005.

41. Soer R, Reneman MF, Speijer BLGN, Coppes MH, Vroomen PCAJ. Clinimetric properties of the EuroQol-5D in patients with chronic low back pain. Spine J. 2012;12:1035-9. https://doi.org/10.1016/j.spinee.2012.10.030.

42. Bilbao A, García-Pérez L, Arenaza JC, García I, Ariza-Cardiel G, Trujillo-Martín $\mathrm{E}$, et al. Psychometric properties of the EQ-5D-5L in patients with hip or knee osteoarthritis: reliability, validity and responsiveness. Qual Life Res. 2018;27:2897-908. https://doi.org/10.1007/s11136-018-1929-x.

43. Oh B, Cho B, Choi H-C, Son K-Y, Park SM, Chun S, et al. The influence of lower-extremity function in elderly individuals' quality of life (QOL): an analysis of the correlation between SPPB and EQ-5D. Arch Gerontol Geriatr. 2014:58:278-82. https://doi.org/10.1016/j.archger.2013.10.008.

44. Eggermont LHP, Bean JF, Guralnik JM, Leveille SG. Comparing pain severity versus pain location in the MOBILIZE Boston study: chronic pain and lower extremity function. J Gerontol Ser A Biol Sci Med Sci. 2009;64A:763-70, https://doi.org/10.1093/gerona/glp016.

45. Kwon S, Perera S, Pahor M, Katula JA, King AC, Groessl EJ, et al. What is a meaningful change in physical performance? Findings from a clinical trial in older adults (the LIFE-P study). J Nutr Health Aging. 2009;13:538-44. https:// doi.org/10.1007/s12603-009-0104-z.

46. Hwang J, Wang L, Siever J, Del Medico T, Jones CA. Loneliness and social isolation among older adults in a community exercise program: a qualitative study. Aging Ment Health. 2019;23:736-42. https://doi.org/10. 1080/13607863.2018.1450835.

47. Geneen LJ, Moore RA, Clarke C, Martin D, Colvin LA, Smith BH. Physical activity and exercise for chronic pain in adults: an overview of Cochrane reviews. Cochrane Database Syst Rev. 2017;4:CD011279. https://doi.org/10. 1002/14651858.CD011279.pub3.

\section{Publisher's Note}

Springer Nature remains neutral with regard to jurisdictional claims in published maps and institutional affiliations.

Ready to submit your research? Choose BMC and benefit from:

- fast, convenient online submission

- thorough peer review by experienced researchers in your field

- rapid publication on acceptance

- support for research data, including large and complex data types

- gold Open Access which fosters wider collaboration and increased citations

- maximum visibility for your research: over $100 \mathrm{M}$ website views per year

At BMC, research is always in progress.

Learn more biomedcentral.com/submissions 